\title{
A new cytotoxic carbazole alkaloid isolated from the stem bark of Malaysian Clausena excavata
}

\begin{abstract}
Malaysia is one of the richest in its biodiversity in the world. There are not less than 12,000 plants species in its rain forest. The aim of this study is a continuous investigation for medicinal plants in Malaysia, especially the chemical constituents that are poses significant activities, i.e. anti-cancer. Clausena excavata (Rutaceae) has been known as a very rich in carbazole alkaloids, coumarins and limonoids species. In the present study, one new carbazole alkaloid, 1,8-dihydroxy-3-formyl-4- prenylcarbazole (Clausine-TH), and two other known compounds, Clausenarin (coumarin) and Clausine-K (carbazole alkaloid), were isolated from the methanol extract of the stem bark of Clausena excavata, collected from Kedah, Malaysia. Structures of these compounds were confirmed by various spectroscopic analyses including GC-MS, NMRs, and FTIR. All pure compounds isolated were tested for their cytotoxicity against CEM-SS cell lines, with the Clausine-TH and Clausine-K gave a very strong activity with an IC50 value of $2.1 \mu \mathrm{g} / \mathrm{mL}$ and $5.1 \mu \mathrm{g} / \mathrm{mL}$, respectively.
\end{abstract}

Keyword: Clausena excavata; Carbazole alkaloid; Clausine`TH; Clausine`K; Clausenarin; CEM'SS cells line. 